\title{
Komunikasi Interpersonal antara Orang Tua dan Anak Remaja serta Identitas Diri Remaja: Studi di Bina Keluarga Remaja Parupuk Tabing, Koto Tangah, Padang, Sumatera Barat
}

\author{
Agus Irianto, Hasdi Aimon, Herman Nirwana, dan Agung Tri Prasetia \\ Universitas Negeri Padang, Jalan Prof. Dr. Hamka Air Tawar Padang, Sumatera Barat \\ Korespondensi: Agus Irianto (e-mail: prof.agus.irianto@gmail.com)
}

\begin{abstract}
Abstrak
Tujuan penelitian ini adalah mendeskripsikan komunikasi interpersonal antara orang tua dengan anak remajanya serta ketercapaian identitas remaja guna pembinaan program Bina Keluarga Remaja (BKR) oleh petugas dan konselor. Metode yang digunakan merupakan bagian dari pengembangan model ADDIE. Penyusunan tes melibatkan tiga ahli serta pelaksaannya dibantu oleh Pembina BKR dan konselor. Instrumen yang digunakan berbentuk pertanyaan dan pengukuran kepribadian yang menggunakan Skala Likert. Analisis data dilakukan dengan deskripsi dan hasil analisis menunjukkan bahwa tingkat komunikasi antara orang tua dan anak remajanya masih sedang dan cenderung rendah. Tingkat kelayakan materi berada pada kategori sangat layak. Untuk itu, perlu dikembangkan modul yang dapat digunakan oleh orang tua dan anak remajanya yang dapat membentuk komunikasi interpersonal efektif antara orang tua dan anak remajanya.
\end{abstract}

Kata kunci: komunikasi interpersonal, ketercapaian identitas, Bina Keluarga Remaja

\section{Interpersonal Communication between Parents and Adolescents and Identity of Yourself: Study at Development Cadres Family Teen of Parupuk Tabing, Koto Tangah, Padang, West Sumatera}

\begin{abstract}
This reseachaims to describe interpersonal communication between parentand child foradolesence identity achievement to be used by Community Development Cadres Family Teen (BKR) or counselor. The method used was part of ADDIE model development. The properness test was done by three experts and the practicality test done by Community Development Cadres Family Teen $(B K R)$ or counselor. The instrumens used Likert Scale and quistionnaire. The data gathered in this research was analyzed by using descriptive statistic analysis. Based on these result, there is a low level of communication between parent and child for adolesence identity achievement. The feasibility level of the component is in a very viable category. The conclusion was that the module developed was appropriate and could be used to help parent and child to improved their effective interpersonal communication for adolesence identity achievement.
\end{abstract}

Keywords: interpersonal communication, identity achievement, Community Development Cadres Family Teen 
Komunikasi Interpersonal antara Orang Tua dan Anak Remaja serta Identitas Diri Remaja: Studi di Bina Keluarga Remaja Parupuk Tabing, Koto Tangah, Padang, Sumatera Barat

\section{Pendahuluan}

Masa remaja merupakan suatu masa atau periode penentu untuk periode dewasa. Dalam periode ini tampak perubahan demi perubahan yang begitu mencolok dan pesat, baik dari segi fisik maupun psikis, sehingga individu tersebut tidak dapat dikatakan anak-anak, tetapi belum juga dapat dikatakan dewasa. Hal ini sesuai dengan pendapat Sarwono (2001:51) yang menjelaskan bahwa masa remaja adalah masa peralihan dari anak-anak ke dewasa, bukan hanya dalam artian psikologis, tetapi juga dalam artian secara fisik. Perubahan fisik yang terjadi itulah yang menjadi gelaja primer dalam pertumbuhan remaja, sedangkan perubahan psikologis muncul, antara lain, sebagai akibat dari perubahanperubahan fisik itu.

Selain terjadi perubahan dan batas usia itu tentunya pada masa remaja ini tidak terlepas dari tahap-tahap perkembangan secara psikologis yang harus dilalui dengan baik. Erikson (dalam Marcia, 1980) menjelaskan bahwa remaja berada dalam tahap perkembangan dengan adanya dikotomi kondisi, yaitu kondisi ikatan identitas melawan kondisi kebingungan peran (identitas). Lebih jauh Erikson menjelaskan bahwa dalam kehidupan sepanjang hayat yang dilalui manusia, terdapat delapan tahap perkembangan psikologi sosial yang harus dilalui manusia dan di setiap tahap itu terdapat dua kondisi yang berlawanan, Hidayat (2011) menjelaskan kondisi yang berlawanan ini memiliki makna berupa impact dari kondisi sosial yang ada di sekitar manusia tersebut. Secara tegas, disebutkan bahwa kondisi yang berlawanan tersebut akan menjadi kekuatan dasar yang akan memengaruhi perkembangan kepribadian manusia hingga akhir hayatnya.
Delapan tahap perkembangan psikosial menurut Erikson (dalam Hall dan lindzey, 2004) adalah sebagai berikut:

1. kepercayaan dasar versus kecurigaan dasar (0 - 1 tahun)

2. otonomi versus rasa malu-malu $(1-3$ tahun)

3. inisiatif versus rasa bersalah $(3-5$ tahun)

4. kerajinan versus inferioritas $(5-11$ tahun)

5. ikatan identitas versus kebingungan peran (12 - 18 tahun)

6. intimasi versus isolasi ( $18-35$ tahun)

7. generativity versus stagnasi $(35-55$ tahun)

8. intergritas ego versus keputusasaan (lebih dari 55 tahun)

Kemudian Ahman (dalam Supriatna, 2011) menjelaskan terdapat tiga faktor dominan yang memengaruhi proses perkembangan remaja, yaitu faktor pembawaan (heredity), faktor lingkungan (environment), dan faktor waktu (time). Dalam melewati tahap perkembangan tersebut, seorang remaja pastinya membutuhkan lingkungan sebagai landasan empiris perkembangannya. Lingkungan yang mendukung dan mendorong perkembangan remaja tentu saja akan menyebabkan tahap perkembangan remaja menjadi ikatan identitas. Sebaliknya, lingkungan yang tidak mendukung akan mengarahkan perkembangan psikososial remaja ke arah kebingungan peran atau krisis identitas.

Secara umum, lingkungan rumah merupakan lingkungan yang sangat memengaruhi perkembangan remaja. Remaja sebagai anak di rumah mendapatkan pengalaman dan pemahaman yang banyak dari orang tua sebagai pendidik dan pengarah di rumah. Semua aspek harus ditanamkan ke 
dalam diri anak, seperti budaya, kepribadian, daninteraksi. Selain itu, rumahjuga merupakan bagian dari pendidikan karena merupakan lingkungan pendidikan (environment of educational). Dalam hal ini, rumah menjadi tempat subjek-subjek dalam rumah, seperti ayah, ibu, dan anak, melakukan fungsi dan kewajiban mereka, seperti yang disampaikan Notoatmodjo (dalam Supriatna, 2011: 29).

Orang tua merupakan pengasuh dan manajer anak di dalam keluarga. Banyak perilaku yang dimunculkan oleh anak bersumber dari orang tuanya. Dalam teori belajar sosial yang dikembangkan oleh Albert Bandura (1986), dijelaskan bahwa seorang anak adalah bobo doll (boneka yang meniru suara) dari perilaku orang tuanya. Ini berarti pengaruh orang tua terhadap anaknya sangat besar. Selain itu, ada banyak temuan tentang perubahan kondisi keluarga terhadap tercapainya tugas perkembangan anak, seperti penelitian Hetherington dan Stanley-Hagan (2002) yang menemukan bahwa 40 persen dari anak-anak di Amerika yang orang tuanya mengalami perceraian kelak akan mengalami perceraian juga dalam pernikahannya. Dengan demikian, dapat ditarik kesimpulan bahwa orang tua merupakan pengasuh, manajer, dan guru yang memberikan pengaruh besar terhadap anak, sedangkan hilangnya pengaruh yang baik akan mengakibatkan remaja kehilangan identitas.

Dariyo (2004) menjelaskan bahwa orang tua yang komunikatif merupakan salah satu ciri yang akan membantu perkembangan anak untuk mencapai identitas diri dengan baik. Komunikasi yang kurang baik antara orang tua dan anak dapat mengakibatkan perilaku negatif pada anak. Sebagaimana diketahui bahwa hubungan antara orang tua dan anak merupakan hubungan antarpribadi. Saad (2003) mengungkapkan bahwa kualitas hubungan antarpribadi akan memberi pengaruh yang besar terhadap perilaku individu, terutama anak dan remaja.

Lebih lanjut Rakhmat (Saad, 2003) mengungkapkan bahwa hubungan dengan orang tua seyogianya diwarnai oleh prinsip saling menjalin komunikasi dan membangun relasi yang dapat mendorong terjadinya hubungan yang sehat. Menurut Papalia dan Feldman (2014), perkembangan yang penting untuk diketahui orang tua mencakup aspek psikososial, yang terdiri atas etnik, identitas, hubungan antarsebaya, hubungan dengan orang tua, hubungan dengan orang tua kandung, anti sosial, dan kenakalan remaja.

Pemerintah juga memiliki perhatian yang besar terhadap perkembangan remaja karena remajalah yang akan menjadi generasi penerus. Hal tersebut dapat dibuktikan dengan adanya program Bina Keluarga Remaja(BKR). BKR merupakan salah satu program yang dikembangkan oleh Badan Kependudukan Keluarga Berencana Nasional (BKKBN) dalam upaya menciptakan ketahanan keluarga dan mewujudkan peningkatan kualitas remaja sebagai implementasi Undang-Undang Nomor 52 Tahun 2009 tentang Perkembangan Kependudukan dan Pembangunan Keluarga yang dalam pengelolaan programnya didasarkan pada Peraturan Kepala BKKBN Nomor 109/PER/F2/2012. Program Bina Keluarga Remaja (BKR) merupakan salah satu kegiatan yang sangat strategis dalam mengupayakan terwujudnya sumber daya manusia potensial melalui upaya meningkatkan pengetahuan dan keterampilan keluarga dalam mengasuh dan membina tumbuh kembang remaja melalui peran orang tua dalam keluaraga. Selain itu, adanya program BKR ini diharapkan dapat mengatasi meningkatnya kecenderungan perilaku seks bebas di kalangan remaja. Namun, BKR dilaksanakan situasi ketika media sosial 
Komunikasi Interpersonal antara Orang Tua dan Anak Remaja serta Identitas Diri Remaja: Studi di Bina Keluarga Remaja Parupuk Tabing, Koto Tangah, Padang, Sumatera Barat

sangat populer di kalangan remaja. Selain itu, curahan hati remaja cenderung dilakukan kepada teman dekat dibandingkan dengan kepada orang tuanya.

Dewantara (2010) menyebutkan bahwa komunikasi interpersonal yang bagus antara orang tua kepada anaknya menyebabkan berkurangnya kenakalan remaja. Sejalan dengan itu, Bintoro (2016) juga meneliti tentang pola komunikasi interpersonal keluarga, motivasi berprestasi, dan prestasi belajar remaja. Dalam penelitian tersebut, peneliti mengorelasikan ketiga variabel tersebut dan menemukan bahwa komunikasi interpersonal keluarga menjadi faktor penentu karena variabel ini mampu memengaruhi dua variabel lainnya. Dengan demikian, dapat dikatakan bahwa komunikasi interpersonal antara orang tua dan anak menjadi fungsi vital dalam perkembangan kepribadian remaja. Penelitian itu juga menekankan bahwa komunikasi interpersonal orang tua dan anak menjadi aspek sentral perkembangan kepribadian remaja.

Kusumaningrum (2012) yang meneliti tentang hubungan komunikasi orang tua-anak dengan ketercapaian identitas remaja akhir menemukan bahwa terdapat korelasi yang sangat erat antara dua variabel tersebut. Jika dilihat dari variabel yang diteliti, penelitian ini dapat dijadikan riset terkait pentingnya model komunikasi interpersonal yang efektif bagi orang tua dalam membantu remaja mencapai identitiy achievement. Hasil penelitian Soldatova (2013) menunjukkan bahwa ada beberapa faktor yang memengaruhi kondisi identitas diri remaja, yaitu dukungan sosial keluarga, berupa komunikasi, motivasi, dan dukungan adaptasi. Kesesuaian penelitian ini berada pada variabel identitas ego dan temuan-temuan berupa faktor yang memengaruhi tercapainya kondisi identitas ego yang baik. Agnes (2009) yang meneliti tentang pencapaian identitas diri remaja menemukan bahwa kondisi orang tua, entah orang tua kandung atau angkat atau tiri, tidak memengaruhi secara langsung pencapaian identitas.

Berdasarkan masalah yang terjadi, peneliti tertarik untuk mendeteksi komunikasi interpersonal antara orang tua dan anak dalam pencapaian identitas diri remaja. Hasil deteksi tersebut akan menggambarkan konten mana yang harus mendapat penekanan atau penguatan untuk mengembangkan media pembelajaran berupa modul agar dapat digunakan oleh petugas BKR atau konselor dalam memberikan pelayanan. Hal ini didasarkan pada argumen bahwa dengan menggunakan modul, anggota BKR dalam hal ini orang tua dan anak remajanya dapat melakukan kegiatan belajar sendiri tanpa kehadiran pengajar (petugas BKR/kader/ konselor) secara langsung. Dengan kata lain, anggota BKR dapat belajar mandiri dan aktif sehingga diharapkan memperoleh pemahaman dan pengetahuan yang baru sesuai dengan tujuan yang ingin dicapai. Media modul ini juga sering disebut bahan instruksional mandiri karena petugas BKR/ konselor tidak harus secara langsung memberi pelajaran atau mengajarkan sesuatu kepada para anggota BKR dengan tatap muka, tetapi cukup dengan memberikan modul.

Berangkat dari hal tersebut, maka peneliti ingin mengembangkan modul komunikasi interpersonal yang efektif serta memfokuskan pada penguasaan pengetahuan dan pemahaman yang dibutuhkan oleh anggota BKR. Peneliti sangat mengharapkan produk yang dikembangkan dalam penelitian ini dapat digunakan dalam praktik pelayanan konseling. Berdasarkan penjelasan di atas, maka penelitian ini dirancang untuk mencapai tujuan pengembangan sebagai berikut. Pertama, menghasilkan pokok-pokok materi yang akan 
mewarnai modul komunikasi interpersonal yang efektif bagi orang tua dan anak dalam pencapaian identitas diri remaja yang layak secara isi. Kedua, mendeskripsikan tingkat keterpakaian modul komunikasi interpersonal yang efektif bagi orang tua dan anak dalam pencapaian identitas diri remaja oleh kader BKR atau konselor.

\section{Metode Penelitian}

Penelitian ini merupakan penelitian pengembangan (research \& development). Prosedur pengembangan yang diterapkan dalam penelitian ini mengikuti langkah-langkah pengembangan menurut model ADDIE yang meliputi Analyze, Design, Development, Implementation, dan Evaluation (Branch, 2009: 2). Kegiatan pengembangan produk yang dilakukan peneliti ini hanya sampai pada tahap uji kelompok kecil atau uji keterpakaian produk oleh kader BKR atau konselor. Subjek uji coba dalam penelitian ini terdiri atas tenaga ahli dalam bidang bimbingan dan konseling untuk melakukan uji kelayakan terhadap produk dan tenaga praktisi, yaitu kader BKR atau konselor untuk menilai uji keterpakaian dari produk yang telah dirancang. Sasaran penelitian adalah BKR di Parupuk Tabing, Kecamatan Koto Tangah, Padang yang berjumlah 30 keluarga.

Tahapan penelitian diawali dengan menetapkan sampel penelitian melalui survei kasus yang ada di BKR seluruh Kota Padang. Berdasarkan survei ditemukan adanya kasus yang perlu pembinaan khusus, yaitu pada kelompok BKR di Parupuk Tabing, Kecamatan Koto Tangah Kota Padang. Dari 30 keluarga yang ada, ditetapkan 11 keluarga dengan jumlah 15 orang remaja yang memiliki kasus terkait komunikasi interpersonal dan pencapaian identitas diri remaja. Selanjutnya peneliti menyusun instrumen dalam bentuk kuisioner dengan Skala Likert dan menganalisis secara kuantitatif kondisi komunikasi interpersonal orang tua dan anak serta kondisi identitas diri remaja yang ada di BKR Parupuk Tabing. Diketahui bahwa instrumen yang digunakan pada uji tingkat validitas (item analysis) dan reliabilitasnya (Cronbach's Alpha) dinyatakan valid per item dan reliabel $(0,714)$.

Hasil analisis tersebut akan menjadi pertimbangan dalam menentukan desain modul komunikasi interpersonal orang tua dan anak yang efektif serta pencapaian identitas diri remaja optimal. Setelah materi didesain, diuji kelayakannya oleh ahli untuk dapat dikembangkan menjadi modul.

\section{Pembahasan}

Hasil penyekoran identitas diri dan komunikasi orang tua dengan anak remajanya dapat dilihat pada Tabel 1 dan 2 .

Berdasarkan Tabel 1, dapat dilihat bahwa skor identitas diri remaja yang tidak tercapai, khususnya adalah pada aspek identity achievement. Walaupun ada yang memperoleh nilai sangat tercapai, nilai maksimal belum tercapai dan jumlahnya masih sedikit. Pada total skor terlihat bahwa tingkat ketercapaiannya antara 61,07 sampai dengan 67,6 pada tiga aspek. Sementara itu, komponen yang satunya lagi masih sangat rendah. Dengan memperhatikan kondisi tersebut, maka masih perlu penanganan yang serius melalui pembuatan modul yang menyentuh seluruh komponen identitas diri remaja sehingga tingkat ketercapaian seluruh komponen menjadi tinggi (di atas 90)

Tabel 2 menjelaskan bahwa komunikasi orang tua dan anak remajanya sangat memprihatinkan karena seluruh komponen masih pada tingkat sedang. Walaupun ada yang mencapai tingkatan baik, hanya satu 
Komunikasi Interpersonal antara Orang Tua dan Anak Remaja serta Identitas Diri Remaja: Studi di Bina Keluarga Remaja Parupuk Tabing, Koto Tangah, Padang, Sumatera Barat

Tabel 1 Skor Identitas Diri Remaja

\begin{tabular}{|c|c|c|c|c|c|c|c|c|}
\hline \multirow{2}{*}{$\begin{array}{r}\text { Resp. } \\
1\end{array}$} & \multicolumn{2}{|c|}{$\begin{array}{c}\text { Identity } \\
\text { Achievment }\end{array}$} & \multicolumn{2}{|c|}{ Moratorium } & \multicolumn{2}{|c|}{ Foreclosure } & \multicolumn{2}{|c|}{$\begin{array}{c}\text { Identity } \\
\text { Diffusiion }\end{array}$} \\
\hline & 36 & $\begin{array}{l}\text { Tdk } \\
\text { tercapai }\end{array}$ & 54 & sedang & 84 & $\begin{array}{l}\text { Sangat } \\
\text { tercapai }\end{array}$ & 46 & sedang \\
\hline 2 & 42 & Sedang & 50 & sedang & 80 & tercapai & 48 & sedang \\
\hline 3 & 46 & Sedang & 54 & sedang & 58 & sedang & 80 & tercapai \\
\hline 4 & 46 & Sedang & 50 & sedang & 80 & tercapai & 58 & sedang \\
\hline 5 & 36 & $\begin{array}{l}\text { Tdk } \\
\text { tercapai }\end{array}$ & 48 & sedang & 52 & sedang & 80 & tercapai \\
\hline 6 & 46 & Sedang & 82 & $\begin{array}{l}\text { Sangat } \\
\text { tercapai }\end{array}$ & 68 & ercapai & 52 & sedang \\
\hline 7 & 48 & Sedang & 82 & $\begin{array}{l}\text { Sangat } \\
\text { tercapai }\end{array}$ & 52 & sedang & 50 & sedang \\
\hline 8 & 38 & $\begin{array}{l}\text { Tdk } \\
\text { tercapai }\end{array}$ & 58 & sedang & 88 & $\begin{array}{l}\text { Sangat } \\
\text { tercapai }\end{array}$ & 62 & tercapai \\
\hline 9 & 38 & $\begin{array}{l}\text { Tdk } \\
\text { tercapai }\end{array}$ & 46 & sedang & 46 & Sedang & 82 & $\begin{array}{l}\text { Sangat } \\
\text { tercapai }\end{array}$ \\
\hline 10 & 40 & $\begin{array}{l}\text { Tdk } \\
\text { tercapai }\end{array}$ & 82 & $\begin{array}{l}\text { Sangat } \\
\text { tercapai }\end{array}$ & 58 & Sedang & 62 & tercapai \\
\hline 11 & 46 & Sedang & 82 & $\begin{array}{l}\text { Sangat } \\
\text { tercapai }\end{array}$ & 62 & tercapai & 66 & tercapai \\
\hline 12 & 24 & $\begin{array}{l}\text { Tdk } \\
\text { tercapai }\end{array}$ & 48 & sedang & 50 & Sedang & 86 & $\begin{array}{l}\text { Sangat } \\
\text { tercapai }\end{array}$ \\
\hline 13 & 42 & Sedang & 54 & sedang & 70 & tercapai & 80 & baik \\
\hline 14 & 40 & $\begin{array}{l}\text { Tdk } \\
\text { tercapai }\end{array}$ & 60 & sedang & 84 & $\begin{array}{l}\text { sangat } \\
\text { tercapai }\end{array}$ & 58 & sedang \\
\hline 15 & 38 & $\begin{array}{l}\text { Tdk } \\
\text { tercapai }\end{array}$ & 66 & tercapai & 82 & $\begin{array}{l}\text { sangat } \\
\text { tercapai }\end{array}$ & 60 & sedang \\
\hline Total & 40,40 & $\begin{array}{l}\text { Tidak } \\
\text { tercapai }\end{array}$ & 61,07 & Tercapai & 67,60 & Tercapai & 64,67 & Tercapai \\
\hline
\end{tabular}

Sumber: Olahan Data Primer, 2018

yang mencapai sangat baik pada komponen kesamaan. Jika tingkat komunikasi ini tidak dibenahi, maka kondisi itu akan menghambat hubungan baik antara orang tua dan anak remajanya yang semakin banyak dipengaruhi oleh IT dan media sosial.
Penilaian terhadap identitas diri remaja menunjukkan bahwa aspek tingkat ketidaktercapaian masih memprihatinkan. Hal itu. terutama untuk identity achievement dengan persentase 26,67 persen yang dinyatakan sangat tidak tercapai dan kriteria ketercapaian 
Tabel 2 Skor Komunikasi Orang Tua dan Anak Remaja

\begin{tabular}{|c|c|c|c|c|c|c|c|c|c|c|}
\hline \multirow{2}{*}{$\begin{array}{r}\text { Resp. } \\
1\end{array}$} & \multicolumn{2}{|c|}{ Keterbukaan } & \multicolumn{2}{|c|}{$\begin{array}{l}\text { Perilaku } \\
\text { Positif }\end{array}$} & \multicolumn{2}{|c|}{ Empati } & \multicolumn{2}{|c|}{$\begin{array}{l}\text { Perilaku } \\
\text { Suportif }\end{array}$} & \multicolumn{2}{|c|}{ Kesamaan } \\
\hline & 44 & Sedang & 50,0 & sedang & 67,5 & baik & 80,0 & baik & 68,0 & baik \\
\hline 2 & 64 & Baik & 60,0 & sedang & 62,5 & baik & 63,3 & baik & 44,0 & sedang \\
\hline 3 & 52 & Sedang & 26,7 & $\begin{array}{l}\text { tidak } \\
\text { baik }\end{array}$ & 40,0 & $\begin{array}{l}\text { tidak } \\
\text { baik }\end{array}$ & 40,0 & $\begin{array}{l}\text { tidak } \\
\text { baik }\end{array}$ & 48,0 & sedang \\
\hline 4 & 60 & Sedang & 66,7 & Baik & 67,5 & baik & 60,0 & sedang & 64,0 & baik \\
\hline 5 & 48 & Sedang & 53,3 & sedang & 55,0 & sedang & 46,7 & sedang & 48,0 & sedang \\
\hline 6 & 56 & sedang & 60,0 & sedang & 57,5 & sedang & 73,3 & baik & 40,0 & $\begin{array}{l}\text { tidak } \\
\text { baik }\end{array}$ \\
\hline 7 & 56 & sedang & 46,7 & sedang & 52,5 & sedang & 60,0 & sedang & 68,0 & baik \\
\hline 8 & 64 & baik & 63,3 & baik & 60,0 & sedang & 76,7 & baik & 92,0 & $\begin{array}{l}\text { sangat } \\
\text { baik }\end{array}$ \\
\hline 9 & 64 & baik & 56,7 & sedang & 67,5 & baik & 60,0 & sedang & 68,0 & baik \\
\hline 10 & 64 & baik & 53,3 & sedang & 55,0 & sedang & 46,7 & sedang & 52,0 & sedang \\
\hline 11 & 60 & sedang & 56,7 & sedang & 42,5 & sedang & 50,0 & sedang & 40,0 & $\begin{array}{l}\text { tidak } \\
\text { baik }\end{array}$ \\
\hline 12 & 40 & $\begin{array}{l}\text { tidak } \\
\text { baik }\end{array}$ & 53,3 & sedang & 30,0 & $\begin{array}{l}\text { tidak } \\
\text { baik }\end{array}$ & 40,0 & $\begin{array}{l}\text { tidak } \\
\text { baik }\end{array}$ & 32,0 & $\begin{array}{l}\text { tidak } \\
\text { baik }\end{array}$ \\
\hline 13 & 28 & $\begin{array}{l}\text { tidak } \\
\text { baik }\end{array}$ & 40,0 & $\begin{array}{l}\text { tidak } \\
\text { baik }\end{array}$ & 35,0 & $\begin{array}{l}\text { tidak } \\
\text { baik }\end{array}$ & 40,0 & $\begin{array}{l}\text { tidak } \\
\text { baik }\end{array}$ & 44,0 & sedang \\
\hline 14 & 52 & sedang & 70,0 & baik & 70,0 & baik & 63,3 & baik & 68,0 & baik \\
\hline 15 & 56 & sedang & 56,7 & sedang & 60,0 & sedang & 70,0 & baik & 56,0 & sedang \\
\hline Total & 53,9 & sedang & 54,2 & sedang & 54,8 & sedang & 58,0 & sedang & 55,5 & sedang \\
\hline
\end{tabular}

Sumber: Olahan Data Primer, 2018

identity achievement yang tidak tercapai 44,67 persen, serta belum ada yang masuk dalam kriteria tercapai maupun sangat tercapai. Aspek moratorium, foreclosure, dan identity diffusion masih didominasi oleh tingkat cukup tercapai. Angka-angka tingkat ketercapaian dapat dilihat pada Tabel 3.

Sementara itu, hasil penumpulan data dari lima komponen komunikasi, yaitu keterbukaan, perilaku positif, empati, perilaku sportif, dan kesamaan, menunjukkan bahwa komponen keterbukaan dan perilaku positif dari komunikasi antara orang tua dan anak remaja sangat memprihatinkan. Dari kedua komponen tersebut tidak ada yang dalam kondisi sangat baik atau nol persen. Dominasi tingkat penilaian terletak di tingkat sedang antara 33,33 persen sampai 50 persen. Oleh karena itu, perlu pembinaan yang lebih serius, terutama pada komponen keterbukaan dan perilaku positif. Angka klasifikasi dan persentase tingkat komunikasi dapat dilihat pada Tabel 4 . 
Tabel 3 Identitas Diri Remaja

\begin{tabular}{lrrrr}
\hline \multicolumn{1}{c}{ Kriteria } & $\begin{array}{c}\text { Identity } \\
\text { Achievement }\end{array}$ & Moratorium & Foreclosure & $\begin{array}{c}\text { Identity } \\
\text { Diffusion }\end{array}$ \\
\hline Sangat Tercapai & 0,00 & 12,00 & 18,67 & 16,67 \\
Tercapai & 0,00 & 18,67 & 24,67 & 20,00 \\
Cukup Tercapai & 28,67 & 36,67 & 35,33 & 35,33 \\
Tidak Tercapai & 44,67 & 28,00 & 18,67 & 26,00 \\
Sangat Tidak Tercapai & 26,67 & 4,67 & 2,67 & 2,00 \\
\hline \multicolumn{1}{c}{ Total } & 100 & 100 & 100 & 100 \\
\hline
\end{tabular}

Sumber: Olahan Data Primer, 2018

Tabel 4 Komunikasi Orang Tua dan Anak Remaja

\begin{tabular}{lrrrrr}
\hline \multicolumn{1}{c}{ Kriteria } & Keterbukaan & $\begin{array}{c}\text { Perilaku } \\
\text { Positif }\end{array}$ & Empati & $\begin{array}{c}\text { Perilaku } \\
\text { Supoprtif }\end{array}$ & Kesamaan \\
\hline Sangat Baik & 0,00 & 0,00 & 5,00 & 6,67 & 8,00 \\
Baik & 16,00 & 14,44 & 15,83 & 21,11 & 16,00 \\
Sedang & 45,33 & 50,00 & 38,33 & 37,78 & 33,33 \\
Tidak Baik & 30,67 & 27,78 & 30,00 & 24,44 & 30,67 \\
Sangat Tidak Baik & 8,00 & 7,78 & 10,83 & 10,00 & 12,00 \\
\hline \multicolumn{1}{c}{ Total } & 100 & 100 & 100 & 100 & 100 \\
\hline
\end{tabular}

Sumber: Olahan Data Primer, 2018

Tabel 5 Uji Keterpakaian Komponen tentang Identitas Diri dan Komunikasi Interpersonal Orang Tua dan Anak

\begin{tabular}{|c|c|c|c|c|c|c|c|}
\hline \multirow[t]{2}{*}{ No } & \multirow{2}{*}{ Komponen } & \multicolumn{2}{|c|}{ Skor Ahli } & \multirow{2}{*}{$\begin{array}{l}\text { Skor } \\
\text { ahli }\end{array}$} & \multirow{2}{*}{$\begin{array}{c}\sum \text { Skor } \\
\text { ideal }\end{array}$} & \multirow[t]{2}{*}{$\%$} & \multirow[t]{2}{*}{ Kategori } \\
\hline & & A & B & & & & \\
\hline 1. & $\begin{array}{l}\text { Identitas diri (Identity } \\
\text { Achievement, } \\
\text { Moratorium, Foreclosure, } \\
\text { Identity Diffusion) }\end{array}$ & 18 & 17 & 35 & 40 & 87,5 & SL \\
\hline 2 & $\begin{array}{l}\text { Komunikasi } \\
\text { Interpersonal yang } \\
\text { efektif (keterbukaan, } \\
\text { perilaku positif, empati, } \\
\text { perilaku suportif, } \\
\text { kesamaan) }\end{array}$ & 17 & 17 & 34 & 40 & 85 & SL \\
\hline
\end{tabular}

Keterangan: SL (Sangat Layak)

Sumber: Olahan Data Primer, 2018 
Selanjutnya data yang telah dipaparkan tersebut dijadikan pokok pikiran desain modul komunikasi interpersonal yang efektif bagi orang tua dan anak untuk pencapaian identitas diri remaja. Data statistik uji keterpakaian komponen modul oleh ahli dapat dilihat pada Tabel 5.

Berdasarkan uji keterpakaian komponen identitas diri yang terdiri atas aspek identity achievement, moratorium, foreclosure, dan identity diffusion, dinilai bahwa keseluruhan aspek tersebut perlu dijadikan sebagai landasan pengembangan media berupa modul yang akan digunakan dalam program BKR untuk pengembangan identitas diri remaja. Sejalan dengan itu, komponen komunikasi interpersonal orang tua dan anak dengan aspek keterbukaan, perilaku positif, empati, dan perilaku suportif juga dinilai dapat mengembangkan kemampuan komunikasi interpersonal orang tua dan anak di kelompok BKR.

\section{Kesimpulan}

Berdasarkan pembahasan dan analisis data di atas, dapat disimpulkan bahwa identitas diri remaja masih belum memperoleh ketercapaian yang tinggi, demikian pula dengan komunikasi orang tua dengan anak remajanya yang masih sangat tidak baik. Sementara itu, tingkat keterpakaian materi modul komunikasi interpersonal orang tua dan anak, serta identitas diri berada pada kategori sangat layak. Kedua komponen ini memerlukan modul yang memuat pembinaan seluruh komponen identitas diri remaja dan komunikasi antara orang tua dan anak remajanya.

\section{Daftar Pustaka}

Agnes, Yurika. 2012. "Pencapaian Identitas Diri pada Remaja yang Memiliki Ibu Tiri”. Jurnal IImiah Psikologi UG Jurnal Vol 5 No 2.
Bandura, A. 1986. Social Foundations of Thought and Action. Englewood cliffs, $\mathrm{NJ}$ : Prentice Hall.

Bintoro, Fachrudin Rahmat. 2016. "Pola Komunikasi Interpersonal Keluarga, Motivasi berprestasi dan Prestasi Belajar". Jurnal Komnas Vol 1 No 18.

Branch, Robert Maribe. 2009. Instructional Design: The ADDIE Approach. New York: Springer Science and Business Media, LCC.

Dariyo, Agoes. 2004. Psikologi Perkembangan

Dewasa Muda. Jakarta: Grasindo.

Dewantara, Apri Catur. 2010. "Pengaruh Kualitas Komunikasi Orang Tua dengan Anak dan Lingkungan Pergaulan terhadap Kenakalan Siswa Kelas VIII SMP Negeri 2 Delanggu". Indegenous Vol 2 No 1.

Hall, Calvin S. dan Gardner Lindzey. 1993. Teori-Teori Psikodinamik (Klinis). Editor A. Supratikya. Yogyakarta: Kanisius.

Hetherington, E. M and M. Stanley-Hagan. 2002. "Parenting in Divorced and Remarried Families, in M. Bornstein (ed). Handbook of Parenting, pp. 287-316. 2nd end. Mahwah, NJ: Lawrence Erlbaum.

Kusumaningrum, Jatika dan Hepi Wahyuningsih. 2012. "Hubungan Komunikasi Interpersonal Orang tuaanak dengan Ketercapaian Identitas diri Remaja". Psikologika Vol 17, No 1.

Marcia, James. 1980. Identity in Adolesence.

New York: Wiley

Papalia, E. D dan Feldman, R. T. 2014. Meyelami Perkembangan Manusia: Experience Human Development. Jakarta: Salemba Humanika.

Saad, Hasballah M. 2003. Perkelahian

Pelajar. Yogyakarta: Galang Press

Sarwono, Sarlito W. 2001. Psikologi Remaja. Jakarta: Raja Grafindo Persada.

Shapiro, Roger L. 1978. "The Adolesence, the Therapist and the Family: the Management 
Komunikasi Interpersonal antara Orang Tua dan Anak Remaja serta Identitas Diri Remaja: Studi di Bina Keluarga Remaja Parupuk Tabing, Koto Tangah, Padang, Sumatera Barat

of Eksternal Resistances to Psychoanalitic

Therapy of Adolesencents". Journal of Adolesence 10: 3-10.

Soldatova, E.L. dan I.A Shlyapnikova. 2013. "Ego-identity in the Structure of Personality Maturity". Procedia - Social and Behavioral Science 86: 283 - 288.

Supriatna, Mamat. 2011. "Model Konseling Aktualisasi Diri untuk Mengembangkan Kecakapan Pribadi Mahasiswa". Disertasi.

Tidak diterbitkan. Bandung: PPS UPI. 